\title{
Patients' Perception and Nurses' Concerns after Nursing Educational Program about Recovery Phase following Cardiothoracic Surgery
}

\author{
Inshrah Roshdy Mohammad* \\ Assistant Professor of Medical Surgical Nursing, Faculty of Nursing, Minia University \\ *Corresponding Author: Inshrah Roshdy Mohammad, Assistant Professor of Medical Surgical \\ Nursing, Faculty of Nursing, Minia University, Egypt. Email: sosomohamd19@yahoo.com
}

\begin{abstract}
Background: There should be functional guidelines provided for patients with cardiac surgery at the time of recovery stage, in which it should be continued from six to eight weeks as well it may be utilized as guidelines for passing certain risk factors. Aim: the present study was designed to evaluate the effect of nursing educational program about recovery phase following cardiothoracic surgery on patients' perception and nurses' concerns.
\end{abstract}

Design: Quasi-experimental research design was used.

Subjects: A purposive study subjects was designed, and included two study groups from patients of post cardiothoracic surgery and staff nurses who assigned to work with these patients.

Setting: The present study was performed in cardiothoracic university hospital at Minia Governorate. Two study questionnaires were used to accomplish the aim of this study which developed by the researcher. The first questionnaire consisted of two parts $1^{\text {st }}$ part concerned the socio-demographic data from both study groups (patients and staff nurses), $2^{\text {nd }}$ part was used to evaluate the effect of nursing educational program through knowledge perception questions that covered relevant points from the major content area of the education program, and composed of nineteenth questions. The second questionnaire was used to assess patient's satisfaction regarding outpatient clinic services after cardiothoracic surgery, and included eleven questions.

Results of the current study showed that, highest percentage (77.5\%) among participated group of patients had satisfactory knowledge level about recovery phase of post cardiac surgery while the rest of them had unsatisfactory level of knowledge. There was a highly statistical significant difference between knowledge regarding recovery phase for post cardiac surgery among participated group of nurses $(P=.001 *)$. The study recommended that, there should pre-admission appointment schedule prior to the day of surgery to review the test results and supply education for the patient and prepared him/ her both clinically and psychologically before surgery then shorten hospital stay.

Keywords: Cardiothoracic Surgery, Recovery Phase, Patients' Perception.

\section{INTRODUCTION}

Aortic stenosis (AS) considered to be the predominately recurrent disease among acquired heart disease of valvular in the industrialized countries of west, as well the its growing and spread is extremely raised with age (Kapoor \& Kapoor, 2009). Valve implantation via the use of trans-catheter of aortic can direct care to a major improvement regarding quality of patient's life through three months after transplantation of valve (Bodenheimer \& Pham, 2010).
Trans-catheter aortic valve implantation (TAVI) over the recent years, was elucidated to be the most safe procedure for valve disease as well it can be conducted and achieved through noticeable low- and midterm outcomes (Zajarias \& Cribier, 2009; Bleiziffer et al., 2009). Amelioration in surgeries, bypass for cardiopulmonary, and myocardial safeguard mechanism as well as the better care during perioperative has been facilitate the execution of open-heart surgery with a degree of the 
mortality rates and morbidity rates acceptance (Krane et al., 2009).

Development and improvement of healthcare have a convenient action for the patient length of stay in hospital after the heart surgery; however, the little stay length has not been go with the reinforced assistance in order to cover and decrease the space between the acute care in hospital and the community care in home (Takach, 2011). Moreover, the knowledge of how to provide nursing management and follow up for theses patient is still minimal which can direct the patient's quality of life to be low and poor. Thus, the practitioner-managed model for nurse to provide follow-up care; can be with an effective manner diminish the space and gap between hospital and primary care that provided to cardiac surgery patients (Sawatzky, Christie, \& Singal, 2013).

The studies of practitioner nurse in critical care has been displayed the evidences for lowering hospital costs which can be shown in patient's length of stay, investigations; patient's complication as for infection; morbidity and mortality rates, and patient's (re)admission. Also, at the international level the practitioners' nurse of critical care units considered the best one for evidencing the essential positive patient care and service as well as the high quality of nursing outcomes.

Practitioner models of critical care nursing can be deemed as cost effective model, this is a result of the proper, right, effective and efficient care delivery of critical care nursing (Fry, 2011). Also, the services of primary care can be implemented to patients by physicians or the non-physician practitioners, which can be as nurse practitioners and physician assistants; as the both of whom hold a graduated license, and have the authority to assess, diagnose, and provide treatment to patients (Bodenheimer \& Pham, 2010).

There are many effective directions and instructions that can be performed for patients with cardiac surgery at the time of recovery stage; this instruction were lasted from six to eight weeks to be effective; as well as theses instructions and procedures can be applied as guidelines for managing specific risk factors at the follow-up care. Theses instructions can encompass; decrease and relief patient's pain; care for incision of surgery; medications; reversion to his/ her activities as in work and sex; rehabilitation of the heart; driving; suitable diet; proper sleep and emotions Clevelandclinic.org.

\section{AIM OF THE STUDY WAS}

To evaluate the effect of nursing educational program about recovery phase following cardiothoracic surgery on patients' perception and nurses' concerns.

\section{The present study was designed to achieve the following objectives:}

1. Construction of nursing educational program about recovery phase following cardiothoracic surgery for staff nurses and patients

2. Investigation of the nursing educational program effectiveness on patients and staff nurses.

3. Assessment of patient's satisfaction regard cardio-thoracic outpatient clinic services.

\section{RESEARCH HYPOTHESIS}

Patients' perception and nurses concerns will be improve post application of nursing educational program about first phase of recovery post cardiothoracic surgery

\section{SubJeCt AND MethodS}

\subsection{Study Design}

Quasi-experimental (pre/ posttest) research study design was used in this study.

\subsection{Study Subjects}

A purposive study subjects was selected in this study; this was included two study groups from patients post cardiothoracic surgery and staff nurses who assigned to work with this patients.

- First study group subjects: this was included all patients who attended the cardiothoracic surgical department to have cardiac surgery during the period of data collection which stated from March, to June 2018; the patient subjected number was $(\mathrm{n}=40)$. An inclusion criterion was designed in this study to select the patient subjects such as: patient whose age $\geq 18$ years; who are able to speak and read Arabic; who have no previous cardiac surgery; and who agreed to participate in this study. The exclusion criteria for those patients were as follows: patient who had post-operative complications, such as heart block, angina, fever, uncontrolled arrhythmia; and patient who have malignant type of arrhythmia. 
- Second study group: was include all staff nurses who working in cardio-thoracic surgical department, critical care unit post cardio-thoracic surgery and cardio-thoracic out-patient clinic, and who agreed to participate in the study, the nurses subject number was (n.=15).

\subsection{Study Setting}

The fieldwork of the present study was performed in cardiothoracic university hospital at Minia Governorate (cardio-thoracic surgical department, critical care unit post cardiothoracic surgery and cardio-thoracic outpatient out-patient clinic).

\subsection{Study Tools}

Two study tools (questionnaire) were used to accomplish the aim of the current study, and these tools were developed by the researcher for the purpose of data collection.

- The first questionnaire: this tool was consisted of two parts; the $\mathbf{1}^{\text {st }}$ part: was concerned about the basic sociodemographic data of study groups' subject (patients and staff nurses) and it was included sex, age, educational status and occupational status...ect. The $\mathbf{2}^{\text {nd }}$ part: was used to evaluate the knowledge perception of study subject about the effect of nursing educational program through questions covered the major content area of the education program, it was composed of nineteenth (19) questions. Each question in the questionnaire had two options (yes or no) and collected from the both study groups (during pre-operative time) prior to the implementation of the intervention program and re-tested after three months of the operation. Content of question remained the same for tow testing sessions.

- The second questionnaire: this tool was used to assess patient's satisfaction regarding the outpatient clinic services after cardiothoracic surgery. It was included eleven (11) questions. Each question in the questionnaire was measured by three options of likert scale (very satisfied $=3$, satisfied $=2$, unsatisfied $=1$ ).

\subsection{Ethical Considerations}

Official permissions to conduct the study were obtained from ethics committee at Faculty of Nursing, Minia University, as well from Director of Cardiothoracic University Hospital at Minia governorate. Aim of the research was explained to the participants. Informed consent from the participants was taken before starting the interview and informed them that all data obtained are confidential.

\subsection{Content Validity and Reliability}

The study tools were constructed by the researchers, as assessment questionnaire. Content validity ascertained by five jury expertise from medical and surgical nursing staff. The reliability estimated for the intervention nursing education program, knowledge, and patient's satisfaction questionnaires were (0.83); the scale coefficient indicated that these measures were adequately reliable.

\subsection{Pilot Study}

The pilot study was chosen randomly and it was carried out in cardiothoracic university hospital on $10 \%$ from the both studied group (patients \& staff nurses) for two different periods, to pretesting the study knowledge questionnaire about education program for nursing intervention and patient's satisfaction questionnaire. The results of the pilot study revealed that the educational program was clear and understandable; the questions of the knowledge and satisfaction questionnaire were revised for content clarity, applicability and arrangement of the items needed. The patients required 5-6 sessions to cover the program intervention. The time required for each session ranged from 10- to 25 minute.

\subsection{Limitations of the Study}

The study subjects were selected from one hospital; therefore the findings of the study can be valid for that specific context only. Since the sample was small, the generalization of the data is limited. Patients were dropped out for following reasons: 6 patient did not complete all parts of the education program, 5 patient refused to participate after few days for unknown reasons, 6 patients did not complete the follow up, 3 patients died prior to their participation in the study, and 5 patients had experienced complications after being participated in the study

\subsection{Study Methods}

The study group of patients who met the study criteria were approached on 1- to 2 day before surgery and explanation of the study objectives was done. The demographic data were obtained from both groups and the pre- test of knowledge questionnaire was conducted on the studied groups (nurses and patients). Teaching materials 
which were used in these sessions included models, illustration, discussion and provision for patient's the written information in brochure. The brochure was translated into Arabic language and was easily understandable wards; which was consisted of the important issues and the major content of educational program. All teaching sessions were held by individual rather than group instruction and this was due to the variability of the patient location. Teaching sessions were done for $10-25$ minute, and each session was performed to complete the program.

The study was lasted for 6 months and the data was collected from March to August 2018. Firstly, the researcher was collected the data through personal interview, and subjects' agreement were taken; then the researcher collected the first questionnaire that have sociodemographic data; then assessed the knowledge regarding first phase of recovery for post cardiothoracic surgery from studied sample (patient and nurses).

Secondly, educational program about first phase of recovery for post cardiothoracic surgery was provided for the patient's and his relatives on discharge day after assessing his/her needs by the researcher through pretest. Third, post-test was done for the assessment of knowledge regarding first phase of recovery for post cardiothoracic surgery from studied subjects (patient and nurses) and the second questionnaire (patients' satisfaction) after three months from patient's discharge.

\subsection{Statistical Analysis}

An IBM compatible PC was used to store and analyze the data as well as to produce graphic presentation of important results. Calculations were done by means of statistical software package namely" SPSS". Data was tabulated and statistical analyzed to evaluate effect of Educational Instruction about First Phase of Recovery Post Cardiothoracic Surgery on Patients' Satisfaction and Nurses Concerns. It's include percentage, and chi square correlation were done between the essential parameters using Pearson's correlation tests " $r$ ".

\section{STUDY RESULTS}

Table1. Distribution of the personal data regarding to participated group from patients $(n=40)$

\begin{tabular}{|c|c|c|}
\hline Socio demographic data of patients & $(\mathrm{N}=40)$ & $\%$ \\
\hline \multicolumn{3}{|l|}{ Age } \\
\hline - 20-30years & 4 & 10 \\
\hline - 31-41years & 18 & 45 \\
\hline - 42 years & 18 & 45 \\
\hline \multicolumn{3}{|c|}{ Mean \pm SD = 2.35+0.662 } \\
\hline \multicolumn{3}{|l|}{ Sex } \\
\hline - Male & 22 & 55 \\
\hline - Female & 18 & 45 \\
\hline \multicolumn{3}{|l|}{ Qualifications } \\
\hline - Illiterate & 10 & 25 \\
\hline - $\quad$ Read and writ & 7 & 17.5 \\
\hline - $\quad$ Intermediate education & 12 & 30 \\
\hline - University education & 11 & 27.5 \\
\hline \multicolumn{3}{|l|}{ Employment } \\
\hline • Work & 17 & 47.5 \\
\hline - Not work & 23 & 57.5 \\
\hline \multicolumn{3}{|l|}{ Chronic diseases } \\
\hline • Hypertension & 5 & 12.5 \\
\hline - $\quad$ Hypertension and diabetes & 5 & 12.5 \\
\hline - $\quad$ Cardiac & 6 & 15 \\
\hline - $\quad$ No & 24 & 60 \\
\hline
\end{tabular}

Table 1 Shows that, less than half (45\%) from participated group of patients had age group 31 to more than 42 years old and the mean average of age was 2.35+0.662; and more than half $(55 \%)$ from them were male. As regards to qualification level, the table represented that, highest percentage (30\%) of patients group had intermediate level of education; but lowest percentage $(17.5 \%)$ of them can read and write although, majority of them had work. Lastly as related to presence or not of chronic diseases among participated group of patient, results found that two third $(60 \%)$ of them hadn't any chronic diseases. 
Patients' Perception and Nurses' Concerns after Nursing Educational Program about Recovery Phase following Cardiothoracic Surgery

Table2. Distribution of the personal data regarding to staff nurses $(n=15)$

\begin{tabular}{|c|c|c|}
\hline Socio demographic data of nurses & $(\mathrm{no}=15)$ & $\%$ \\
\hline \multicolumn{3}{|l|}{ Age } \\
\hline - $\quad$-20-24years & 4 & 26.7 \\
\hline - $\quad$-25-29years & 7 & 46.7 \\
\hline - $\quad-<30$ years & 4 & 26.7 \\
\hline \multicolumn{3}{|l|}{ Mean \pm SD $=2.00+0.756$} \\
\hline \multicolumn{3}{|l|}{ Gender } \\
\hline - Male & 6 & 40 \\
\hline - $\quad$ Female & 9 & 60 \\
\hline \multicolumn{3}{|l|}{ Qualification } \\
\hline - $\quad$ Bachelor & 2 & 26.7 \\
\hline - $\quad$ Technical institute of nursing & 9 & 46.7 \\
\hline - $\quad$ School of nursing & 4 & 26.7 \\
\hline \multicolumn{3}{|l|}{ Place of work } \\
\hline - Cardio-thoracic critical unit & 7 & 46.7 \\
\hline - $\quad$ Cardio-thoracic surgical department & 7 & 46.7 \\
\hline - Cardio-thoracic outpatient clinic & 1 & 6.7 \\
\hline \multicolumn{3}{|l|}{ Years of experience } \\
\hline$\bullet \quad 1-5$ years & 5 & 33.3 \\
\hline - $\quad<6 y e a r s$ & 10 & 66.7 \\
\hline
\end{tabular}

Table 2 Revealed that, less than half percent (46\%) from participated group of nurses had age group between 25 to 29 years old; and highest percent of their gender was female (60\%). Also, around half $(46.7 \%)$ of nurses were graduated from technical institute of nursing; and highest

Table3. Comparison between participated group from nurses' knowledge regard recovery phase post cardiac surgery $(N=15)$ percent of them worked at cardio-thoracic critical unit or cardio -surgical ward represented with equal percentage $(46.7 \%)$. Finally the participated group of nurses had more than six years at their work's experience $(66.7 \%)$.

\begin{tabular}{|c|c|c|c|c|c|c|c|c|c|c|c|c|c|c|}
\hline \multirow[t]{3}{*}{ Items } & \multicolumn{4}{|c|}{ Pre program } & \multicolumn{4}{|c|}{ Post program1 } & \multicolumn{4}{|c|}{ Post program 2} & \multirow{3}{*}{$\mathbf{X}^{2}$} & \multirow{3}{*}{$\mathbf{P}$} \\
\hline & \multicolumn{2}{|c|}{$\begin{array}{l}\text { Satisfactory } \\
<70\end{array}$} & \multicolumn{2}{|c|}{$\begin{array}{l}\text { Un } \\
\text { satisfactory } \\
\geq 70\end{array}$} & \multicolumn{2}{|c|}{$\begin{array}{l}\text { Satisfactory } \\
<70\end{array}$} & \multicolumn{2}{|c|}{$\begin{array}{l}\text { Un } \\
\text { satisfactory } \\
\geq 70\end{array}$} & \multicolumn{2}{|c|}{$\begin{array}{l}\text { Satisfactory } \\
<70\end{array}$} & \multicolumn{2}{|c|}{$\begin{array}{l}\text { Un } \\
\text { satisfactory } \\
\geq 70\end{array}$} & & \\
\hline & $\mathbf{N}$ & $\%$ & $\mathbf{N}$ & $\%$ & $\mathbf{N}$ & $\%$ & $\mathbf{N}$ & $\%$ & $\mathbf{N}$ & $\%$ & $\mathbf{N}$ & $\%$ & & \\
\hline $\begin{array}{l}\text { Nurses } \\
\text { knowledge }\end{array}$ & 0 & 0 & 15 & 100 & 15 & 100 & 0 & 0 & 15 & 100 & 0 & 0 & 126.4 & $.001 * *$ \\
\hline $\begin{array}{l}\text { Mean } \pm \\
\text { SD }\end{array}$ & \multicolumn{4}{|c|}{$8.40 \pm 2.35$} & \multicolumn{4}{|c|}{$17.80 \pm 1.42$} & \multicolumn{4}{|c|}{$17.27 \pm 1.53$} & & \\
\hline
\end{tabular}

Table 3 Results found that, there was highly statistical significant difference between surgery among participated group of nurses. $\mathrm{P}=.001^{*}$ knowledge regard recovery phase post cardiac

Table4. Frequency distribution by percentage regarding to knowledge's levels regard recovery phase post cardiac surgery among participated group from patients $(N=40)$

\begin{tabular}{|l|l|c|c|c|c|}
\hline \multirow{3}{*}{ Variable } & \multicolumn{4}{|c|}{ Post- program } & \multirow{2}{*}{ Mean+ SD } \\
\cline { 2 - 5 } & \multicolumn{2}{|c|}{ Satisfactory < 70 } & \multicolumn{2}{c|}{ Unsatisfactory > 70 } & \\
\cline { 2 - 5 } & $\mathrm{N}$ & $\%$ & $\mathrm{~N}$ & $\%$ & $\mathbf{1 . 7 7 + 0 . 4 2 2}$ \\
\hline Patient's knowledge & 31 & 77.5 & 9 & 22.5 & \\
\hline
\end{tabular}

Table 4 Shows that, highest percentage $(77.5 \%)$ recovery phase post cardiac surgery while the among participated group of patients had satisfactory level of knowledge regarding rest of same group had unsatisfactory level of knowledge. The mean average was $\mathbf{1 . 7 7 + 0 . 4 2 2}$. 


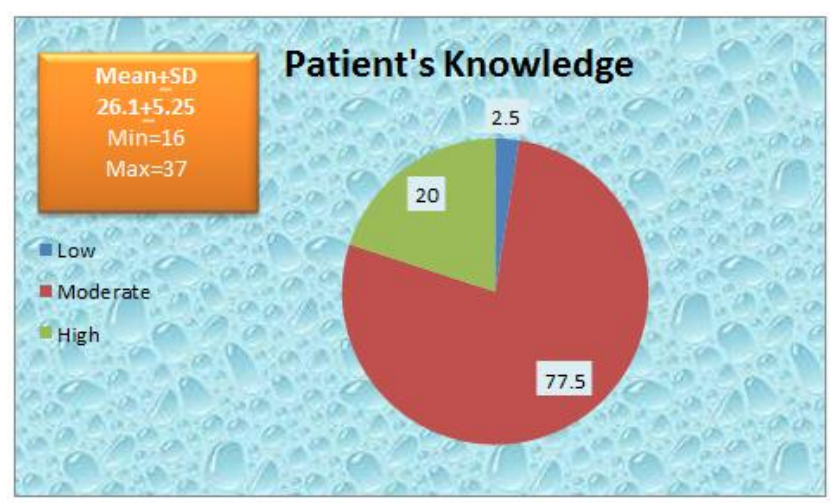

Figure1. The frequency distribution by percentage regarding to satisfaction levels regard Cardio-thoracic outpatient clinic services among participated group from patients $(N=40)$

Figure1 illustrated that, the highest percentage $(77.5 \%)$ among participated group of patients had moderate satisfaction level regarding cardio-thoracic outpatient clinic services; while lowest percentage $(2.5 \%)$ among same group had low satisfaction level.

Table5. Correlation between both studied groups (patients \& nurses) regarding to their knowledge's of recovery phase post cardiac surgery

\begin{tabular}{|c|c|c|c|c|}
\hline Studied group (1) & \multicolumn{2}{|c|}{ Studied group (2) } & Z Test & $\mathbf{P}$ \\
\hline & Mean & $\underline{\text { SD }}$ & & \\
\hline $\begin{array}{c}\text { Mean }+ \text { SD }= \\
15.40 \pm 3.25\end{array}$ & $\begin{array}{l}\underline{\text { Mean }}(1)=17.80 \\
\operatorname{Mean}(1)=17.27\end{array}$ & $\begin{array}{l}\underline{\mathbf{S D}}(1)=1.42 \\
\mathbf{S D}(2)=1.53\end{array}$ & $\begin{array}{l}2.05 \\
2.02\end{array}$ & $\begin{array}{c}0.040 \\
043 \\
\text { N.S. }\end{array}$ \\
\hline
\end{tabular}

Mean + SD (1): results for Nurses' knowledge after one months.

Mean $+S D$ (2): results for Nurses' knowledge after three months.

Table 5 represented that, there was no statistical significant relation between both studied groups (patients \& nurses) regarding to their knowledge's about recovery phase of post cardiac surgery.

\section{DISCUSSION}

After the coronary artery bypass grafting $(\mathrm{CABG})$, there is confined knowledge about the postoperative care for acute physical functional recovery, in which the most research studies that had centered on postoperative physical functional recovery had examined the rehabilitation of cardiac patient in phase II (recovery phase) and phase III (maintenance phase) (C.-W. Lee et al., 2014), (Y. Lee et al., 2013) \&(Y. Lee, Jun, \& Ju, 2012)

Moreover, the role of critical care nurse is very important in which nurses should regularly accomplish their skills of clinical assessment effectively; the clinical assessment that done for peripheral perfusion (neurovascular assessments) are critically crucial for the appraisal and assessing the influence of cardiac output after surgery of the heart valve (van Weert, van Dulmen, Bar, \& Venus, 2003) \& (Senzaki, Isoda, Ishizawa, \& Hishi, 1994). Therefore, the nurse intensively must provide the proper care for the patient early in the postoperative stage after CABG. This acute and intense observation, as well as postoperative inconvenience can intervene with the requirement of patient for his/ her need to sleep in which it could influence the postoperative outcomes with negative effect (Havrilak, 2002).

In this current study the results shows that, there was less than half of participated group from patients who had cardiac surgery were in age group from 31 to more than 42 years old with mean average $2.35+0.66$, this may be related to socioeconomic and genetic risk factors that associated with heart diseases patients, which were commonly present in study setting. This results was not similar with the finding of (Tobita et al., 2016) who mentioned that, the elderly Japanese population with age over 65 years old was most age who had cardiac surgery, which it is predestined to the number of 33.8 million, with the percentage of $26.7 \%$ from the total Japanese population.

Also, in the current study, more than half of participated group from patients were male, this result may be due to male is the one who had high risk for heart diseases as a result of their huge exposure to smoking as well the displaying to stressful situations of life in current study setting. 
Furthermore, results of this study show that, there was a highly statistical significant difference between knowledge regarding recovery phase for post cardiac surgeries among participated group of nurses. This results was consistent with findings of (Moore, 1994) who displayed that disability or surgery complication can be eliminated via the process of supporting patient and his/ her family if they realize the recovery phase. This realization can be fostered by centered on the prospective matters in which the patient may get-together over the recovery phase in home that lasted from one to eight weeks and sometimes continued to six months after surgery. Moreover, educating patient may give a share in smoothing recovery phase in home, as well enhance the excellence of treatment and cost mitigation (Senzaki et al., 1994).

In addition, there was several research studies presented that cardiac surgery patients required to have lot of information regarding their expectation about the recovery phase care at home. Thus, the desire to furnish patients with information before and after surgery of heart believed to be the usually agreeable practice in clinical field; while the information shortage and deficiency at the time of patient hospitalization or after patient discharge from hospital can retard the recovery at this phase (Moore, 1996).

On the other hand, the current study findings illustrated that highest percentage among participated group from patients had satisfactory level regarding their knowledge about recovery phase for postoperative of cardiac surgery, this result may be due to the poor pre-operative knowledge and health education of patient about cardiac surgery looked to be complex issue. This was in same line with result of (Havrilak, 2002) who declared that, global health education for patient who had cardiac surgery can help him/ her to adjust the phase of prohibiting complication of postoperative also, it can fostering positive outcomes of the patient's surgery.

Also, similar finding have been showing by another study of (Beckie, 1989) who pronounced that participated patients in the study group who had the proper and supportive educative program via the telephone, elucidated a significant major level of knowledge than the patient who had no educative program among the control group. Furthermore, (Marshall, Penckofer, \& Llewellyn, 1986) proved that the patient in the study and control group possess a higher level scores regarding total knowledge after cardiac surgery. While (Van Weert et al., 2003) result was incongruent with the present study results in which the findings of his study revealed there is low level of health education knowledge among patient regarding postoperative care for cardiac surgery.

Finally, current results represented that the highest percentage among participated group of patients had moderate level of satisfaction regarding cardio-thoracic outpatient clinic services. This may be illustrated that, the building of current study setting was recently built and had adequate resources and facilities; while participated group of patients complained only from the lack of knowledge and explanation from physicians regarding the treatment and outpatient clinic pharmacy.

\section{RECOMMENDATIONS}

1. Pre-admission appointment should be scheduled prior to the day of surgery in order to review the test results and provide health education for the patient; as well as prepared him both clinically and psychologically before surgery then shorten hospital stay.

2. Regular effective in-service training on pre-operative education for cardiac surgery patients should be provided for intensive care nurses to ensure better patient care and outcomes; also it is crucial for nurses to understand how important it is that families are included in the education process.

3. Replicated, the study to involve a larger population and sample from public and/ or private sector to investigate the preoperative education for patients who undergo cardiac surgery to enhance the generalizability of study results.

4. Reinforcement of education during the follow-up period concerning to the patients' needs.

\section{REFERENCES}

[1] Beckie, T. (1989). A supportive-educative telephone program: impact on knowledge and anxiety after coronary artery bypass graft surgery. Heart \& lung: the journal of critical care, 18(1), 46-55.

[2] Bleiziffer, S., Ruge, H., Mazzitelli, D., Schreiber, C., Hutter, A., Laborde, J.-C., . . . Lange, R. (2009). Results of percutaneous and transapical transcatheter aortic valve implantation performed by a surgical team. 
European Journal of Cardio-Thoracic Surgery, 35(4), 615-621.

[3] Bodenheimer, T., \& Pham, H. H. (2010). Primary care: current problems and proposed solutions. Health Affairs, 29(5), 799-805.

[4] Fry, M. (2011). Literature review of the impact of nurse practitioners in critical care services. Nursing in critical care, 16(2), 58-66.

[5] Havrilak, C. (2002). Streamlining the preoperative process for the open heart surgery patient. NAHAM access management journal, 28(2), 3, 5-3, 5 .

[6] Kapoor, J. R., \& Kapoor, R. (2009). Aortic valve stenosis. The Lancet, 373(9680), 2023.

[7] Krane, M., Bauernschmitt, R., Hiebinger, A., Wottke, M., Voss, B., Badiu, C. C., \& Lange, R. (2009). Cardiac reoperation in patients aged 80 years and older. The Annals of thoracic surgery, 87(5), 1379-1385.

[8] Lee, C.-W., Wang, J.-H., Hsieh, J.-C., Hsieh, T.-C., Wu, Y.-Z., Chen, T.-W., \& Huang, C.-H. (2014). Supervised phase II cardiac exercise therapy shortens the recovery of exercise capacity in patients with acute myocardial infarction. Journal of physical therapy science, 26(9), 1503-1508.

[9] Lee, Y., Jun, I., \& Ju, S. (2012). Impact of Home Exercise Training on Patientswith Acute Myocardial Infarction. Journal of physical therapy science, 24(8), 743-745.

[10] Lee, Y., Lee, J., Seo, H., Kim, K., Min, D., Lee, J., \& Choi, J. (2013). Effects of home-based exercise training with wireless monitoring on the left ventricular function of acute coronary syndrome patients. Journal of physical therapy science, 25(5), 631-633.

[11] Marshall, J., Penckofer, S., \& Llewellyn, J. (1986). Structured postoperative teaching and knowledge and compliance of patients who had coronary artery bypass surgery. Heart \& lung: the journal of critical care, 15(1), 76-82.
[12] Moore, S. M. (1994). Development of discharge information for recovery after coronary artery bypass surgery. Applied Nursing Research, 7(4), 170-177.

[13] Moore, S. M. (1996). The effects of a discharge information intervention on recovery outcomes following coronary artery bypass surgery. International Journal of Nursing Studies, 33(2), 181-189.

[14] Sawatzky, J. A. V., Christie, S., \& Singal, R. K. (2013). Exploring outcomes of a nurse practitioner-managed cardiac surgery follow-up intervention: a randomized trial. Journal of advanced nursing, 69(9), 2076-2087.

[15] Senzaki, H., Isoda, T., Ishizawa, A., \& Hishi, T. (1994). Reconsideration of criteria for the Fontan operation. Influence of pulmonary artery size on postoperative hemodynamics of the Fontan operation. Circulation, 89(3), 11961202.

[16] Takach, M. (2011). Reinventing Medicaid: state innovations to qualify and pay for patientcentered medical homes show promising results. Health Affairs, 30(7), 1325-1334.

[17] Tobita, R., Iwata, K., Kamisaka, K., Yuguchi, S., Tahara, M., Oura, K., . . . Hanafusa, Y. (2016). Clinical characteristics of functional recovery after coronary artery bypass graft surgery in Japanese octogenarians. Journal of physical therapy science, 28(2), 621-625.

[18] van Weert, J., van Dulmen, S., Bär, P., \& Venus, E. (2003). Interdisciplinary preoperative patient education in cardiac surgery. Patient Education and Counseling, 49(2), 105-114.

[19] Zajarias, A., \& Cribier, A. G. (2009). Outcomes and safety of percutaneous aortic valve replacement. Journal of the American College of Cardiology, 53(20), 1829-1836.

Citation: Inshrah Roshdy Patients' Perception and Nurses' Concerns after Nursing Educational Program about Recovery Phase following Cardiothoracic Surgery. ARC Journal of Nursing and Healthcare. 2019; 5(1):45-52. doi: dx.doi.org/ 10.20431/2455-4324.0501005.

Copyright: (0) 2019 Authors. This is an open-access article distributed under the terms of the Creative Commons Attribution License, which permits unrestricted use, distribution, and reproduction in any medium, provided the original author and source are credited. 